\title{
Maturation-promoting factor (MPF) is responsible for the transformation of sperm nuclei to metaphase chromosomes in maturing bovine oocytes in vitro
}

\author{
L. R. Abeydeera, K. Niwa* and K. Okuda \\ Department of Animal Science and Technology, Faculty of Agriculture, Okayama University, \\ Okayama 700, Japan
}

\begin{abstract}
Bovine oocytes at the germinal vesicle stage were inseminated in Brackett and Oliphant's medium in the presence of BSA (10 $\left.\mathrm{mg} \mathrm{ml}^{-1}\right)$, caffeine $\left(5 \mathrm{mmol} \mathrm{l}^{-1}\right)$ and heparin $\left(10 \mu \mathrm{g} \mathrm{ml}^{-1}\right)$. When oocytes were transferred into tissue culture medium (TCM)-199 containing $10 \%$ fetal calf serum (FCS) with or without 6-dimethylaminopurine (6-DMAP; $2 \mathrm{mmol} \mathrm{l}^{-1}$ ) $8 \mathrm{~h}$ after insemination and cultured for $15-40 \mathrm{~h}$ at $39^{\circ} \mathrm{C}$ in $5 \% \mathrm{CO}_{2}$ in air, $74-83 \%$ of oocytes were penetrated and polyspermy $(67-80 \%)$ was common. At $40 \mathrm{~h}$ after culture in 6-DMAP-free medium, $65 \%$ and $63 \%$ of unpenetrated and penetrated oocytes, respectively, reached metaphase II or beyond. A few $(6 \%)$ oocytes were activated and contained both male and female pronuclei. Sperm metaphase chromosomes were observed in $90 \%$ of the penetrated oocytes. Penetration by more than four spermatozoa greatly retarded the meiotic maturation of the oocyte. However, sperm chromosomes were never observed in oocytes cultured in 6-DMAP supplemented medium and oocyte maturation did not proceed beyond the stage of prometaphase I. These results demonstrate the possible participation of maturation-promoting factor in metaphase chromosome formation in spermatozoa.
\end{abstract}

\section{Introduction}

The maturing oocytes of Urechis (Das and Barker, 1976), frog (Moriya and Katagiri, 1976; Elinson, 1977) and mouse (Clarke and Masui, 1986, 1987) possess a strong cytoplasmic activity that can transform sperm nuclei into metaphase chromosomes. We found a similar phenomenon in maturing bovine oocytes (Abeydeera and Niwa, 1992): although the maturing oocyte cytoplasm could transform up to nine sperm nuclei into metaphase chromosomes, the first meiotic maturation was greatly retarded in oocytes penetrated by more than four spermatozoa. A similar finding was also reported for mouse oocytes inseminated at prometaphase I to metaphase I (Clarke and Masui, 1986).

It is well established that maturation-promoting factor (MPF) is a cytoplasmic factor that brings about germinal vesicle breakdown and the subsequent maturational events in oocytes of amphibians (Masui and Markert, 1971; Smith and Ecker, 1971) and starfish (Kishimoto and Kanatani, 1976). This factor is highly conserved among a wide variety of species, and plays a key role in the progression of the cell cycle from interphase to metaphase, in both meiosis and mitosis (Lohka, 1989). According to Kishimoto (1988), MPF is a metaphase-regulating protein. The activity of MPF is controlled by the phosphorylationdephosphorylation processes (Gautier et al., 1989). Taking these results into consideration, the formation of sperm chromosomes in maturing bovine oocytes and the retardation of meiotic

${ }^{*}$ Reprint requests.

Received 21 July 1992. maturation in highly polyspermic oocytes lead to the suggestion of the possible involvement of MPF in the transformation of sperm nuclear chromatin into metaphase chromosomes. If this contention is correct, the disruption of the normal functioning of one process should affect the other.

In starfish (Neant and Guerrier, 1988), mice (Rime et al., 1989) and cows (Fulka et al., 1991; L. R. Abeydeera, K. Niwa and K. Okuda, unpublished observations), 6-dimethylaminopurine (6-DMAP), a purine derivative that blocks protein phosphorylation without affecting the overall rate of protein synthesis can reversibly inhibit the appearance of MPF activity in oocytes at the germinal vesicle stage and its stability in oocytes already undergoing germinal vesicle breakdown (it promotes the appearance of resting nuclei). The present study was designed to examine the relationship between MPF and sperm nuclear transformation in maturing bovine oocytes in vitro by using 6-DMAP.

\section{Materials and Methods}

\section{Fertilization medium}

The basic medium used for the treatment of spermatozoa and the fertilization of oocytes comprised $112.0 \mathrm{mmol} \mathrm{NaCl} \mathrm{l^{-1 }}$, $4.02 \mathrm{mmol} \mathrm{KCl} \mathrm{l}^{-1}, 2.25 \mathrm{mmol} \mathrm{CaCl}_{2} \mathrm{l}^{-1}, 0.83 \mathrm{mmol} \mathrm{NaH} \mathrm{PO}_{4}$ $1^{-1}, 0.52 \mathrm{mmol} \mathrm{MgCl} 1^{-1}, 37.0 \mathrm{mmol} \mathrm{NaHCO}_{3} 1^{-1}, 13.9 \mathrm{mmol}$ glucose $\mathrm{I}^{-1}, 1.25 \mathrm{mmol}$ sodium pyruvate $\mathrm{I}^{-1}$ and $31 \mu \mathrm{g}$ potassium penicillin $\mathrm{G} \mathrm{ml}^{-1}$, but without BSA. This medium was 
essentially the same as that used by Brackett and Oliphant (1975) for the fertilization of rabbit oocytes in vitro, and designated as $\mathrm{BO}$ medium.

\section{Preparation of oocytes}

Bovine ovaries were collected at a local abattoir within $30 \mathrm{~min}$ of slaughter and transported to the laboratory within $1-1.5 \mathrm{~h}$ in $0.9 \% \mathrm{NaCl}$ at $30-32^{\circ} \mathrm{C}$ in a vacuum flask. Oocytes were aspirated from small antral follicles of 3-5 mm diameter with an 18 gauge needle fixed to a $5 \mathrm{ml}$ syringe. Oocytes surrounded by compact cumulus and with an evenly granulated cytoplasm were washed three times in BO medium supplemented with $20 \mathrm{mg} \mathrm{BSA} \mathrm{ml}{ }^{-1}$ (crystallized and lyophilized, essentially globulin free, Sigma Chemical Co., St Louis, MO) and $20 \mu \mathrm{g}$ porcine intestinal mucosal heparin $\mathrm{ml}^{-1}$ (178 United States Pharmacopoeia units $\mathrm{mg}^{-1}$; Sigma Chemical Co.). The washed oocytes (5-10 oocytes) were transferred into $50 \mu \mathrm{l}$ of the same medium and kept under $5 \% \mathrm{CO}_{2}$ in air at $39^{\circ} \mathrm{C}$ for about 30 min before spermatozoa were added. All culture and fertilization media had previously been covered with warm paraffin oil (Nacalai Tesque, Inc., Kyoto) in a polystyrene culture dish $(35 \times 10 \mathrm{~mm}$; Miles Laboratories, Inc., Naperville, IL) and equilibrated with the gas phase and temperature in a $\mathrm{CO}_{2}$ incubator for $2-3 \mathrm{~h}$.

\section{Sperm preparation and in vitro fertilization}

Spermatozoa were treated using the procedures reported by Niwa and Ohgoda (1988). Briefly, a $0.5 \mathrm{ml}$ straw of frozen semen prepared from a Holstein bull (P-123) was thawed in a water bath at $37-39^{\circ} \mathrm{C}$. Spermatozoa were washed twice in $\mathrm{BO}$ medium supplemented with $10 \mathrm{mmol}$ caffeine $\mathrm{l}^{-1}$ (caffeinesodium benzoate, $50: 50(\mathrm{w} / \mathrm{w})$ mixture, Sigma Chemical Co.) by centrifugation at $833 \mathrm{~g}$ for $10 \mathrm{~min}$ each. The sperm pellet was resuspended in the same medium at $5-10 \times 10^{6}$ spermatozoa $\mathrm{ml}^{-1}$. A drop $(50 \mu \mathrm{l})$ of the sperm suspension was introduced into $50 \mu \mathrm{l}$ of the medium that included the oocytes and cultured at $39^{\circ} \mathrm{C}$ in an atmosphere of $5 \% \mathrm{CO}_{2}$ in air. The mixture gave the final concentrations of $2.5-5 \times 10^{6}$ spermatozoa ml $\mathrm{ml}^{-1}$, $10 \mathrm{mg} \mathrm{BSA} \mathrm{ml}^{-1}, 5 \mathrm{mmol}$ caffeine $\mathrm{l}^{-1}$ and $10 \mu \mathrm{g}$ heparin $\mathrm{ml}^{-1}$.

\section{Additional culture with or without 6-DMAP}

Eight hours after insemination, oocytes were washed three times in tissue culture medium (TCM)-199 (with Earle's salts) buffered with $\mathrm{N}$-2-hydroxyethylpiperazine $\mathrm{N}$-2-ethane sulfonic acid (Hepes, $25 \mathrm{mmol} \mathrm{l}^{-1}$ ) and supplemented with $10 \%(\mathrm{v} / \mathrm{v})$ heat-inactivated fetal calf serum (FCS; GIBCO Laboratories, Grand Island, NY), $60 \mu \mathrm{g}$ penicillin $\mathrm{G} \mathrm{ml}^{-1}, 100 \mu \mathrm{g}$ streptomycin $\mathrm{ml}^{-1}$ with or without $2 \mathrm{mmol}$ 6-DMAP $\mathrm{l}^{-1}$ (Sigma Chemical $\mathrm{Co}$.). At the concentration of 2 mmol 6-DMAP $\mathrm{l}^{-1}$, germinal vesicle breakdown of bovine oocytes can be effectively inhibited (Fulka et al., 1991). The washed oocytes (5-10 oocytes) were then transferred into $100 \mu \mathrm{l}$ drops of the respective medium covered with paraffin oil and cultured in a $\mathrm{CO}_{2}$ incubator $\left(5 \% \mathrm{CO}_{2}\right.$ in air at $\left.39^{\circ} \mathrm{C}\right)$ for $15-40 \mathrm{~h}$. A portion of oocytes cultured for $15 \mathrm{~h}$ in the presence of 6-DMAP was washed three times in inhibitor-free medium and cultured in the same medium for another $40 \mathrm{~h}$.

\section{Examination of oocytes}

At $15-40 \mathrm{~h}$ after additional culture, oocytes were freed from cumulus cells by repeated passage through a fine pipette and placed in the centre of four vaseline:paraffin (1:9) spots on a glass slide. After being compressed gently with a cover slip, the oocytes were fixed for $48-72 \mathrm{~h}$ at room temperature in $25 \%$ $(\mathrm{v} / \mathrm{v})$ acetic alcohol, stained with $1 \%(\mathrm{w} / \mathrm{v})$ orcein in $45 \%(\mathrm{v} / \mathrm{v})$ acetic acid as described by Ohgoda et al. (1988) and examined for evidence of oocyte nuclear maturation and transformation of sperm nucleus in penetrated oocytes. Oocytes that were not penetrated by spermatozoa during the insemination served as controls.

\section{Classification of sperm nuclear transformation}

The morphological changes of the sperm nucleus were classified into four categories as reported by Abeydeera and Niwa (1992). Briefly, the four categories were (1) decondensed chromatin, (2) recondensed chromatin, (3) metaphase chromosomes and (4) male pronucleus.

\section{Results}

When oocytes were fertilized in BO medium and subsequently transferred to TCM-199 with or without 2 mmol 6-DMAP $1^{-1}$, most oocytes were penetrated $(74-83 \%)$ and polyspermy (67$80 \%$ ) was common in both; there were no significant differences between different times of examination and between the presence and absence of 6-DMAP (Table 1). In 6-DMAP-free medium, $50 \%(5$ of 10 ) and $28 \%$ (14 of 50 ) unpenetrated and penetrated oocytes reached metaphase $\mathrm{Il}$, respectively, by $15 \mathrm{~h}$ of the additional culture (no significant difference). Maturation proceeded such that $65 \%$ (11 of 17 ) and $63 \%$ (30 of 48 ) of unpenetrated and penetrated oocytes, respectively, reached metaphase II or beyond by $40 \mathrm{~h}$. A few $(6 \%)$ penetrated oocytes were activated (contained female pronuclei) by $40 \mathrm{~h}$. In contrast, examination at 15 and $40 \mathrm{~h}$ after transfer to medium supplemented with 6-DMAP revealed that none of the oocytes reached metaphase II $(P<0.001)$ and most oocytes were arrested between germinal vesicle breakdown to prometaphase I stage regardless of sperm penetration. However, when 30 oocytes cultured in the presence of 6-DMAP for $15 \mathrm{~h}$ were subsequently cultured in 6-DMAP-free medium for $40 \mathrm{~h}, 71 \%$ (5 of 7) and 70\% (16 of 23) unpenetrated and penetrated oocytes reached metaphase II or beyond, respectively, with concomitant appearance of sperm chromosomes in 19 of $23(83 \%)$ penetrated oocytes.

When polyspermy was modest (one to four spermatozoa per oocyte) in the absence of 6-DMAP, it appeared to have no effect on oocyte maturation, because 29 of $42(69 \%)$ oocytes reached metaphase II or beyond. However, when more than four spermatozoa penetrated, development appeared delayed and a significantly $(P<0.001)$ lower proportion $(17 \%)$ of oocytes reached metaphase II or beyond (Table 2). In the medium supplemented with 6-DMAP, none of the oocytes reached metaphase II stage regardless of the number of spermatozoa penetrated per oocyte. 
Table 1. Maturation of bovine oocytes cultured for $15-40 \mathrm{~h}$ after transfer into TCM-199 medium containing $10 \%$ fetal calf serum with $(+)$ or without $(-) 2$ mmol 6-dimethylaminopurine (6-DMAP) $\mathrm{l}^{-1}$ at $8 \mathrm{~h}$ after insemination ${ }^{\mathrm{a}}$

\begin{tabular}{|c|c|c|c|c|c|c|c|c|c|}
\hline \multirow[b]{2}{*}{$\begin{array}{l}\text { Time of } \\
\text { examination } \\
\text { (h after } \\
\text { transfer) }\end{array}$} & \multirow[b]{2}{*}{$\begin{array}{c}\text { Presence } \\
\text { of } \\
\text { 6-DMAP }\end{array}$} & \multirow[b]{2}{*}{$\begin{array}{l}\text { Number of } \\
\text { oocytes } \\
\text { examined }\end{array}$} & \multirow[b]{2}{*}{$\begin{array}{l}\text { Number of } \\
\text { oocytes } \\
\text { penetrated } \\
(\%)\end{array}$} & \multirow[b]{2}{*}{$\begin{array}{l}\text { Number of } \\
\text { polyspermic } \\
\text { oocytes } \\
(\%)^{c}\end{array}$} & \multicolumn{5}{|c|}{ Number of oocytes at the stage of ${ }^{b}$} \\
\hline & & & & & $\begin{array}{l}\text { GV } \\
(\%)^{d}\end{array}$ & $\begin{array}{c}\text { GVBD- } \\
\text { PM-I } \\
(\%)^{d}\end{array}$ & $\begin{array}{l}\text { M-I- } \\
\text { T-I } \\
(\%)^{d}\end{array}$ & $\begin{array}{l}\text { M-II } \\
(\%)^{d}\end{array}$ & $\begin{array}{c}\text { Female } \\
\text { pronucleus } \\
(\%)^{\mathrm{d}}\end{array}$ \\
\hline \multirow[t]{2}{*}{15} & - & 60 & $50(83)$ & $35(70)$ & $0+1(2)$ & $0+9(15)$ & $5+26(52)$ & $5+14(32)^{e}$ & $0+0(0)$ \\
\hline & + & 59 & $44(75)$ & $35(80)$ & $2+4(8)$ & $13+40(92)$ & $0+0(0)$ & $0+0(0)^{t}$ & $0+0(0)$ \\
\hline \multirow[t]{2}{*}{40} & - & 65 & $48(74)$ & $32(67)$ & $0+0(0)$ & $0+6(9)$ & $6+12(28)$ & $11+26(57)^{e}$ & $0+4(6)$ \\
\hline & + & 52 & $41(79)$ & $30(73)$ & $3+7(19)$ & $8+34(81)$ & $0+0(0)$ & $0+0(0)^{f}$ & $0+0(0)$ \\
\hline
\end{tabular}

${ }^{2}$ Oocytes were inseminated in $\mathrm{BO}$ medium supplemented with $10 \mathrm{mg} \mathrm{BSA} \mathrm{ml}^{-1}, 5 \mathrm{mmol}$ caffeine $\mathrm{l}^{-1}$ and $10 \mu \mathrm{g}$ heparin ml ${ }^{1}$. Experiments were repeated three times. ${ }^{\text {'} T h e ~ f i r s t ~ f i g u r e ~ d e n o t e s ~ t h e ~ n u m b e r ~ o f ~ u n p e n e t r a t e d ~ o o c y t e s ~ a n d ~ t h e ~ s e c o n d ~ d e n o t e s ~ t h e ~ n u m b e r ~ o f ~ o o c y t e s ~ p e n e t r a t e d . ~ G V: ~ g e r m i n a l ~ v e s i c l e ; ~ G V B D: ~ G V ~ b r e a k d o w n ; ~}$ PM-I: prometaphase I; M-I: metaphase I; T-I: telophase I; M-II: metaphase II.

'Percentage of the number of oocytes penetrated.

'Percentage of the number of oocytes examined.

${ }^{\mathrm{e}-\mathrm{f}}$ Within each time of examination, values with different superscripts are significantly different $\left(P<0.001 ; \chi^{2}\right.$ test $)$.

Table 2. Effect of the number of spermatozoa penetrated on meiotic maturation of oocytes after transfer into culture medium supplemented with

$(+)$ or without $(-)$ 6-dimethylaminopurine (6-DMAP) ${ }^{\mathrm{a}}$

\begin{tabular}{lccccc}
\hline \multirow{2}{*}{$\begin{array}{l}\text { Number of } \\
\text { spermatozoa } \\
\text { penetrated } \\
\text { per oocyte }\end{array}$} & $\begin{array}{c}\text { Presence } \\
\text { of } \\
\text { 6-DMAP }\end{array}$ & GV & $\begin{array}{c}\text { GVBD- } \\
\text { PM-I }\end{array}$ & $\begin{array}{c}\text { M-I- } \\
\text { T-I }\end{array}$ & $\begin{array}{c}\text { M-II }+ \\
\text { FP }\end{array}$ \\
\cline { 3 - 6 } & - & 0 & 3 & 10 & $26+3^{\text {c,e }}$ \\
$1-4$ & + & 6 & 19 & 0 & $0+0^{\text {c.f }}$ \\
& - & 0 & 3 & 2 & $0+1^{\text {d.e }}$ \\
$\geq 5$ & + & 1 & 15 & 0 & $0+0^{\text {c.e }}$ \\
\hline
\end{tabular}

${ }^{2}$ Oocytes examined $40 \mathrm{~h}$ after transfer were used.

${ }^{\circ} \mathrm{GV}$ : germinal vesicle; GVBD: GV breakdown; PM-I: prometaphase I; MI: metaphase I; T-I: telophase I; M-II: metaphase II; FP: female pronculeus.

$\rightarrow$ Within the presence $(+)$ or absence $(-)$ of 6-DMAP, values with different superscripts are significantly different $\left(P<0.001 ; \chi^{2}\right.$ test).

-i Within each number of spermatozoa penetrated per oocyte, values with different superscripts are significantly different $\left(P<0.001 ; \chi^{2}\right.$ test $)$.

As shown in Table 3, in 6-DMAP-free medium, 78 and $90 \%$ of penetrated oocytes transformed the sperm nucleus to metaphase chromosomes (category 3) by 15 (Fig. 1a) and $40 \mathrm{~h}$, respectively. Only $8 \%$ of oocytes contained male pronuclei together with the female pronucleus. In contrast, sperm metaphase chromosomes were never observed in oocytes cultured in 6-DMAP-supplemented medium $(P<0.001)$. Instead, most of the sperm nuclei were transformed to recondensed (category 2, Fig. 1b) or decondensed (category 1) chromatin.

\section{Discussion}

The results of the present study reconfirm the report of Abeydeera and Niwa (1992) by demonstrating the presence of cytoplasmic activity in maturing bovine oocytes that can transform sperm nuclei into metaphase chromosomes. There is a wealth of information on such transformations of initially dispersed sperm chromatin to chromosomes (Das and Barker, 1976; Moriya and Katagiri, 1976; Elinson, 1977; Clarke and Masui, 1986, 1987). Longo et al. (1991) observed sperm chromosome formation in starfish oocytes inseminated at metaphase I. They suggested that the time of insemination with respect to the stage of meiotic maturation has a significant effect on sperm nuclear transformation and the possible involvement of MPF in sperm chromosome formation. Indeed, in the present study, sperm chromosomes were never observed and oocyte maturation did not proceed beyond the stage of prometaphase I in oocytes examined $15-40 \mathrm{~h}$ after transfer into the culture medium containing 6-DMAP. Both the inability to proceed 
Table 3. Effect of 6-dimethylaminopurine (6-DMAP) on the transformation of the sperm nucleus into metaphase chromosomes ${ }^{a}$

\begin{tabular}{lcccccc} 
Time of & & \multicolumn{3}{c}{ Number of oocytes penetrated with sperm nucleus at the stage of } \\
\cline { 2 - 6 } $\begin{array}{l}\text { examination } \\
\text { (h after } \\
\text { transfer) }\end{array}$ & $\begin{array}{c}\text { Presence } \\
\text { of } \\
\text { 6-DMAP }\end{array}$ & Total & $\begin{array}{c}\text { Decondensed } \\
\text { chromatin } \\
(\%)\end{array}$ & $\begin{array}{c}\text { Recondensed } \\
\text { chromatin } \\
(\%)\end{array}$ & $\begin{array}{c}\text { Metaphase } \\
\text { chromosomes } \\
(\%)\end{array}$ & $\begin{array}{c}\text { Male } \\
\text { pronuclei } \\
(\%)\end{array}$ \\
\hline 15 & - & 50 & $3(6)$ & $8(16)$ & $39(78)^{\mathrm{b}}$ & $0(0)$ \\
& + & 44 & $8(18)$ & $36(82)$ & $0(0)^{\mathrm{c}}$ & $0(0)$ \\
40 & - & 48 & $0(0)$ & $1(2)$ & $43(90)^{\mathrm{b}}$ & $4(8)$ \\
& + & 41 & $7(17)$ & $34(83)$ & $0(0)^{\mathrm{c}}$ & $0(0)$ \\
\hline
\end{tabular}

aocytes were cultured for $15-40 \mathrm{~h}$ after transfer into tissue culture medium (TCM)-199 containing $10 \%$ fetal calf serum (FCS) with (+) or without (-) $2 \mathrm{mmol} 6$-DMAP I ${ }^{1}$ at $8 \mathrm{~h}$ after insemination.

b-Within each time of examination, values with different superscripts are significantly different $\left(P<0.001 ; \chi^{2}\right.$ test).

with meiotic maturation and transformation of sperm chromatin into chromosomes can be accounted for by the loss of MPF in the oocyte cytoplasm owing to the inhibitory effect of 6-DMAP, because subsequent transfer of these oocytes into inhibitor-free medium reinitiated oocyte maturation and promoted the appearance of sperm chromosomes. The results of the present study therefore demonstrate the possible participation of MPF as the cytoplasmic factor in maturing bovine oocytes that is responsible for the transformation of sperm nuclei into metaphase chromosomes. Thus our finding also supports the suggestions made by Clarke and Masui (1987) and Longo et al. (1991) and may also be true for maturing oocytes studied so far which can stimulate the transition of nuclei from other cells (Gurdon, 1968; Ziegler and Masui, 1973, 1976; Balakier and Czolowska, 1977; Balakier, 1978; Masui et al., 1979; Tarkowski and Balakier, 1980; Czolowska et al, 1984; Sorensen et al., 1985) and sperm chromatin (Moriya and Katagiri, 1976; Das and Barker, 1976; Elinson, 1977; Luttmer and Longo, 1988) to metaphase condition.

Clarke and Masui (1986) and Abeydeera and Niwa (1992) have shown that penetration of maturing oocytes by spermatozoa does not delay meiotic maturation, but that polyspermy does. In the study reported here, examination of oocytes following $40 \mathrm{~h}$ of transfer revealed that sperm penetration had no apparent morphological effect on their ability to complete first meiotic maturation, because 65 and $63 \%$ of unpenetrated and penetrated oocytes reached metaphase II or beyond, respectively. Nevertheless, meiotic maturation is greatly retarded when oocytes are penetrated by more than four spermatozoa. As sperm nuclear transformation is also under the influence of MPF (the present study), it is not surprising that the meiotic maturation is affected in highly polyspermic oocytes owing to a possible insufficiency in the amount of MPF required to complete the process of oocyte maturation. A few $(6 \%)$ oocytes inseminated at the GV stage could complete the second meiotic maturation forming female pronuclei and concomitantly the transformed sperm chromosomes developed into male pronuclei. In contrast, although the mouse oocytes inseminated at prometaphase I or metaphase I stage can form sperm metaphase chromosomes, they failed to support male pronuclear formation (Clarke and Masui, 1986). However, such transformation of sperm chromosomes into pronuclei was reported for starfish oocytes inseminated at metaphase I (Longo et al., 1991). Nevertheless, sperm chromosomes were never observed in bovine oocytes inseminated at metaphase I to telophase I, but the penetrated sperm chromatin first became decondensed and then developed to a pronucleus (Chian et al., 1992). The discrepancies observed in these studies could be attributed to species differences.

Among the large number of mammalian species so far investigated, only the immature oocytes (germinal vesicles) of dogs (Mahi and Yanagimachi, 1976), cows (Niwa et al., 1991) and pigs (Wang et al., 1992) can be penetrated with subsequent sperm nuclear decondensation. These results indicate the presence of adequate quantities of the necessary factor(s), such as reduced glutathione (Wiesel and Schultz, 1981; Calvin et al., 1986; Perreault et al., 1988), responsible for decondensation of sperm nuclei in these oocytes. The increasing amounts of MPF at and after germinal vesicle breakdown of bovine oocytes will act upon the decondensed sperm nuclei and the subsequent events coordinate with the stages of oocyte meiotic maturation until the formation of chromosomes. This suggests that the sperm penetrated into an immature bovine oocyte will undergo characteristic changes similar to the oocyte chromatin. If any of the oocytes that reached metaphase II become activated, they will complete the second meiosis and develop female pronuclei. At this time the sperm chromosomes may be influenced by cytoplasmic factors such as male pronuclear growth factor (MPGF; Thibault and Gerard, 1973) or the sperm pronuclear development factor (SPDF; Yanagimachi, 1981) to form the male pronucleus. However, only a few $(6 \%)$ oocytes were activated when inseminated at the germinal vesicle stage (the present study), but a much higher rate was observed for bovine oocytes inseminated just after germinal vesicle breakdown (authors' unpublished observation). There are two possible explanations for the very low activation rate. First, as suggested by Abeydeera and Niwa (1992), the sperm nuclei incorporated into oocytes at the germinal vesicle stage cannot activate the oocytes even after completing maturation. It is possible that those oocytes that did undergo activation may have begun to mature during the in vitro fertilization incubation, and were therefore activated by the penetrating spermatozoa. Second, 

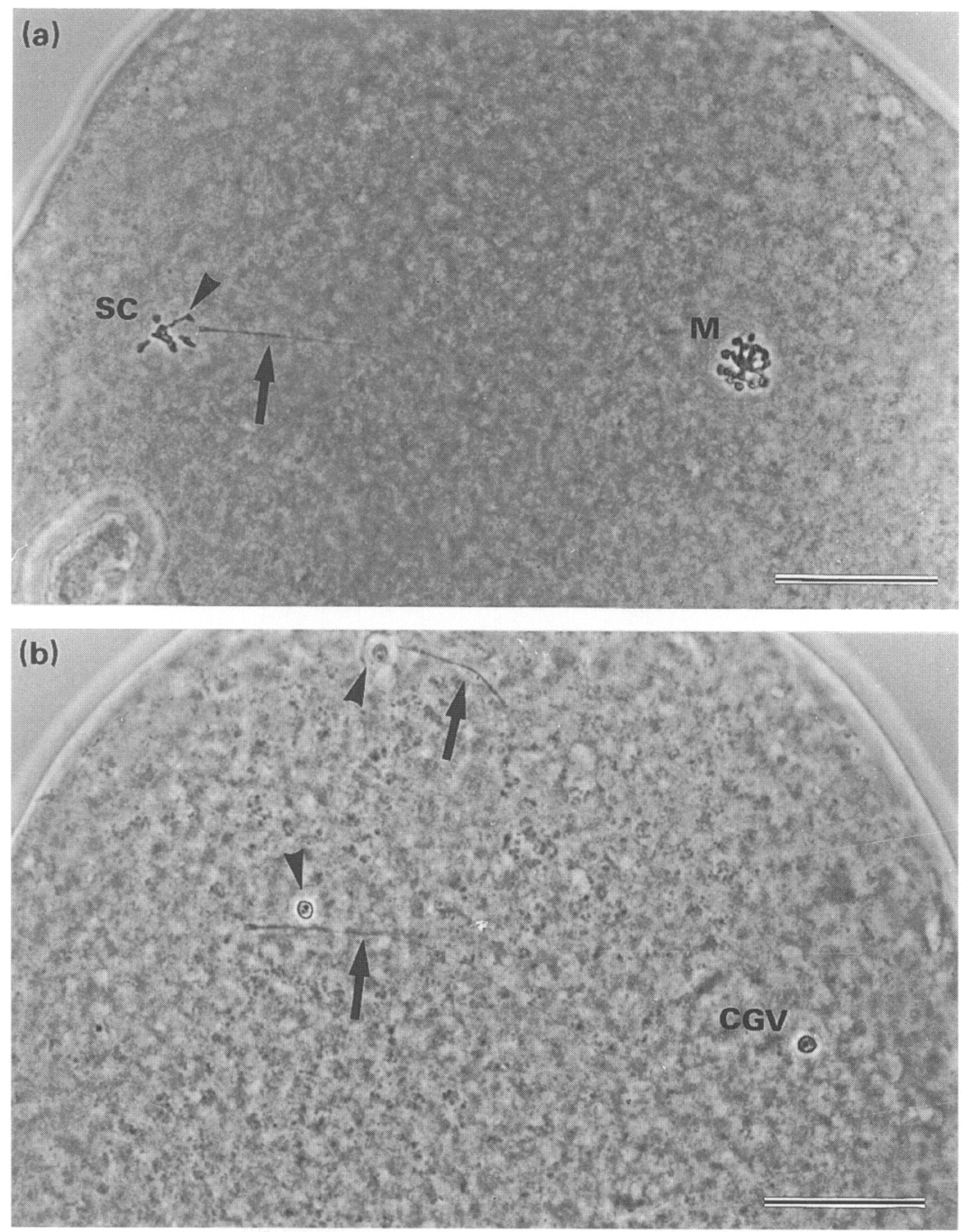

Fig. 1. Oocytes transferred into TCM-199 supplemented (a) with or (b) without 6-dimethylaminopurine (6-DMAP) $8 \mathrm{~h}$ after insemination and further cultured for (a) $15 \mathrm{~h}$ or (b) $40 \mathrm{~h}$. (a) A penetrated oocyte at the stage of metaphase I (M). A sperm nucleus (arrowhead) is transformed to metaphase chromosomes (SC), with a penetrating sperm tail (arrow). (b) A penetrated oocyte at the stage of condensed germinal vesicle (CGV). Two recondensed (arrowheads) sperm nuclei, with penetrating sperm tails (arrows) are visible. One of the recondensed sperm nuclei is out of focus. Bars $=20 \mu \mathrm{m}$.

despite the low activation rate, a fairly high percentage of penetrated oocytes reached metaphase II $(57 \%)$ by $40 \mathrm{~h}$. The ability of in vitro matured oocytes to be activated is an index of their cytoplasmic maturation and bovine oocytes will attain this ability as one of the final steps in the maturation process (Ware et al., 1989). The very low activation rate could therefore be attributed to the inadequate cytoplasmic maturation in those oocytes for the subsequent activation, although nuclear maturation can be completed with a modest polyspermy (one to four spermatozoa per oocyte). Experiments are in progress to examine the validity of the above possibilities.

A portion of this work was supported by Grant-in-Aid for Developmental Scientific Research (No. 03556038) from the Ministry of Education, Science and Culture of Japan.

\section{References}

Abeydeera LR and Niwa K (1992) Ability of in vitro maturing bovine oocytes to transform sperm nuclei to metaphase chromosomes Journal of Reproduction and Fertility 96 565-572

Balakier H (1978) Induction of maturation in small oocytes from sexually immature mice by fusion with meiotic and mitotic cells Experimental Cell Research 112 137-141

Balakier H and Czolowska N (1977) Cytoplasmic control of nuclear maturation in mouse oocytes Experimental Cell Research 110 466-469

Brackett BG and Oliphant G (1975) Capacitation of rabbit spermatozoa in vitro Biology of Reproduction 12 260-274

Calvin HI, Grosshans K and Blake EJ (1986) Estimation and manipulation of glutathione levels in prepubertal mouse ovaries and ova: relevance to sperm nucleus transformations in the fertilized egg Gamete Research 14 265-275

Chian RC, Niwa K and Nakahara H (1992) Effect of sperm penetration in vitro on completion of first meiosis of bovine oocytes arrested at various stages in culture Joumal of Reproduction and Fertility 96 73-78 
Clarke HJ and Masui Y (1986) Transformation of sperm nuclei to the metaphase chromosomes in the cytoplasm of maturing oocytes of the mouse Joumal of Cell Biology 102 1039-1046

Clarke HJ and Masui Y (1987) Dose-dependent relationship between oocyte cytoplasmic volume and transformation of sperm nuclei to metaphase chromosomes Joumal of Cell Biology 104 831-840

Czolowska R, Modlinski JA and Tarkowski A (1984) Behaviour of thymocyte nuclei in non-activated and activated mouse oocytes Joumal of Cell Science 69 19-34

Das NK and Barker C (1976) Mitotic chromosome condensation in the sperm nucleus during postfertilization maturation division in Urechis eggs Joumal of Cell Biology 68 155-159

Elinson RP (1977) Fertilization of immature frog eggs: cleavage and development following subsequent activation Joumal of Embryology and Experimental Morphology 37 187-201

Fulka J Jr, Leibfried-Rutledge ML and First NL (1991) Effect of 6-dimethylaminopurine on germinal vesicle breakdown of bovine oocytes Molecular Reproduction and Development 29 379-384

Gautier J, Matsukawa T, Nurse P and Maller J (1989) Dephosphorylation and activation of $X_{\text {enopus }}$ p $34 \mathrm{cdc} 2$ protein kinase during the cell cycle Nature 339 $626-629$

Gurdon JB (1968) Changes in somatic cell nuclei inserted into growing maturing amphibian oocytes Journal of Embryology and Experimental Morphology 20 401-414

Kishimoto T (1988) Regulation of metaphase by a maturation-promoting factor Development, Growth and Differentiation 30 105-115

Kishimoto T and Kanatani H (1976) Cytoplasmic factor responsible for germinal vesicle breakdown and meiotic maturation in starfish oocytes Nature 260 321-322

Lohka MJ (1989) Mitotic control by metaphase-promoting factor and cdc proteins Joumal of Cell Science 92 131-135

Longo FJ, Cook S and Mathews L (1991) Pronuclear formation in starfish eggs inseminated at different stages of meiotic maturation: correlation of sperm nuclear transformations and activity of the maternal chromatin Developmental Biology $14762-72$

Luttmer SJ and Longo FJ (1988) Sperm nuclear transformations consist of enlargement and condensation coordinate with stages of meiotic maturation in fertilized Spisula solidissima oocytes Developmental Biology 128 86-96

Mahi CA and Yanagimachi R (1976) Maturation and sperm penetration of canine ovarian oocytes in vitro Joumal of Experimental Zoology 196 189-196

Masui Y and Markert CL (1971) Cytoplasmic control of nuclear behavior during meiotic maturation of frog oocytes Joumal of Experimental Zoology 177 $129-146$

Masui Y, Meyerhof PG and Ziegler DH (1979) Control of chromosome behaviour during progesterone-induced maturation of amphibian oocytes Joumal of Steroid Biochemistry 11 715-722

Moriya $\mathbf{M}$ and Katagiri $\mathbf{C}$ (1976) Microinjection of toad sperm into oocytes undergoing maturation division Development, Growth and Differentiation 18 349-356
Neant I and Guerrier P (1988) 6-dimethylaminopurine blocks starfish oocyte maturation by inhibiting a relevant protein kinase activity Experimental Cell Research 176 68-79

Niwa K and Ohgoda $\mathrm{O}$ (1988) Synergistic effect of caffeine and heparin on in vitro fertilization of cattle oocytes matured in culture Theriogenology $\mathbf{3 0}$ 733-741

Niwa K, Park C-K and Okuda K (1991) Penetration in vitro of bovine oocytes during maturation by frozen-thawed spermatozoa Joumal of Reproduction and Fertility $91329-336$

Ohgoda O, Niwa K, Yuhara M, Takahashi S and Kanoya K (1988) Variations in penetration rates in vitro of bovine follicular oocytes do not reflect conception rates after artificial insemination using frozen semen from different bulls Theriogenology 29 1375-1381

Perreault SD, Barbee RR and Slott VL (1988) Importance of glutathione in the acquisition and maintenance of sperm nuclear decondensing activity in maturing hamster oocytes Developmental Biology 125 I81-186

Rime H, Neant I, Guerrier P and Ozon R (1989) 6-dimethylaminopurine (6-DMAP), a reversible inhibitor of the transition to metaphase during the first meiotic cell division of the mouse oocyte Developmental Biology 133 169-179

Smith LD and Ecker RE (1971) The interaction of steroids with Rana pipiens oocytes in the induction of maturation Developmental Biology 25 232-247

Sorensen RA, Cyert MS and Pederson RA (1985) Active maturation-promoting factor is present in mature mouse oocytes Joumal of Cell Biology 100 1637-1640

Tarkowski AK and Balakier H (1980) Nucleo-cytoplasmic interactions in cell hybrids between mouse oocytes, blastomeres and somatic cells joumal of Embryology and Experimental Morphology 55 319-330

Thibault C and Gerard M (1973) Cytoplasmic and nuclear maturation of rabbit oocytes in vitro Annales de Biologie Animale, Biochimie, Biophysique 13 145-156

Wang WH, Uchida M and Niwa K (1992) Effects of follicle cells on in vitro penetration of pig oocytes by cryopreserved, ejaculated spermatozoa journal of Reproduction and Development 38 125-131

Ware CB, Barnes FL, Maiki-Laurila M and First NL (1989) Age dependence of bovine oocyte activation Gamete Research 22 265-275

Wiesel S and Schultz GA (1981) Factors which may affect removal of protamine from sperm DNA during fertilization in the rabbit Gamete Research 4 25-34

Yanagimachi R (1981) Mechanisms of fertilization in mammals. In Fertilization and Embryonic Development in vitro pp 8I-182 Eds L Mastroianni Jr and JD Biggers. Plenum Press, New York

Ziegler DH and Masui Y (1973) Control of chromosome behavior in amphibian oocytes. I. The activity of maturing oocytes inducing chromosome condensation in transplanted brain nuclei Developmental Biology $\mathbf{3 5}$ 283-292

Ziegler DH and Masui Y (1976) Control of chromosome behavior in amphibian oocytes. II. The effect of inhibitors of RNA and protein synthesis on the induction of chromosome condensation Journal of Cell Biology 68 620-628 